\title{
Effect of coir fibers on the tensile and flexural strength of soft marine clay
}

\begin{abstract}
The effects of the mechanical properties of the coir fiber which reinforces soft marine clay were investigated by a series of laboratory tests regarding unconfined-compression, indirect tensile properties, and three point bending. In this study, fiber content was found as the main factor that affected the strength of the soil specimens. The results indicated that for the unconfined compression test at the maximum dry density and optimum moisture content, compressive strength increased with fiber content up to $1 \%$. A similar trend was also found in the tensile strength, flexural strength, and young's modulus of the soil. The strength and ductility increased sharply until the threshold of $1.5 \%$ fiber content. Furthermore, the improvement in the mechanical behavior of the soil mixtures indicates that the use of fibers mixed with soft marine clay as potential building materials for land-based structures.
\end{abstract}

Keyword: Coir fiber; Soft marine clay; Compressive strength; Tensile strength; Flexural strength; Young's modulus; Ductility 